\section{THE INFLUENCE OF} ANISOTHERMAL \section{HARDENING ON THE LOW CARBON STEEL PROPERTIES}

MARTIN PODARIL ${ }^{1}$, JAN MAJERNIK ${ }^{1}$, JIRI SAL $^{2}$

Department of Mechanical Engineering ${ }^{1}$, Departmen of Civil Engineering2, Institute of Technology and Business in

Ceske Budejovice, Ceske Budejovice

DOI : 10.17973/MMSJ.2019_12_2019021

podaril.martin@gmail.com

The purpose of hardening is the increase the hardness of the steel by creating an imbalanced structure. High hardness can be achieved by the formation of a martensitic structure. In some specific cases, we try to obtain a bainitic structure when hardening. In real hardening processes, a martensitic structure is usually achieved on the surface of the body, producing a mixture of martensite, bainite and other types of microstructures in the core of the body. The contribution deals with the influence of anisothermal hardening on selected mechanical properties of EN ISO S235JR (G2) steel. The observed values are the HBW hardness, $\mathrm{Rm}$ strength and hardness $A$. At the hardness measurement locations, the structural steel compositions are metallographically evaluated in the surface of hardened and non-hardened samples that are mutually compared. Subsequently, the influence of hardening on the examined mechanical properties and dependencies descibing the correlation of the structure and hardness of the hardened steels is deduced.

heat treatment of metals, mechanical properties, austenitisation, full-hardening

\section{HEAT TREATMENT OF METALS}

By heat treatment we mean heating to a certain temperature followed by cooling at a certain rate. You can ensue such processes even several times in succession. Strictly speaking, the heat treatment can not be separated from other technological processes, because instead of using a special heating, in many cases, it is possible to cool the metal with a relatively high temperature during the casting or hot forming at a certain rate and thereby achieve the desired effect [Korecký 1965, Kučerová 2016].

The purpose of the heat treatment is either to obtain a as stable structure as possible or to achieve certain nonequilibrium states characterized by particularly advantageous mechanical or other properties [Brezničan 2013, Cacko 2014]. In the first case, the desired result is achieved by simple heating at certain temperature and by slow even cooling. This approach is called annealing. In the latter case, cooling has to be accelerated by hardening and the work is more complex and dependent on the nature of the metal [ČSN 411375 1994].

It is necessary to clarify the influence of higher temperature on the crystallization process of metals. Pure metal elements in the mold state and slowly cooled down by annealing are not changing. At most, metallic crystals become round as a consequence of surface tension at high temperatures [Murcinkova 2013]. However, in metal, we can find internal tension excessing a certain limit, e.g. by casting into the castiron mold the recrystallization may occur [Hluchý 2002]. For less pure metals, the equilibrium is reached less frequently by normal cooling. Various changes can then be expected after annealing, such as equalization of the unevenness of the composition within the crystals of solid solutions, and more or less perfect stabilization of equilibrium in peritectic crystallization For fine segregations, such as some eutectics and crystals form thicker structures due to surface tensions. If the metal contain phases at higher temperatures more soluble than at lower temperatures, their partial or complete dissolution may occur by a sufficiently long heating [Pospíchal 2015]. By a subsequent slow cooling is such phase eliminated in a different form as originally. By fast enough cooling, such segregation can be avoided and thereby altering the properties of the metal. Due to a formation of new phases at higher temperatures, the metal undergoes the recrystallization by heating, its structure is altered and the very fine crystal structure can be achieved according to the rate of transition through the recrystallization temperature - by very fast transition; or very rough crystal structure - by very slow transition [Turtelli 2006]. On this finding is based the annealing of steel castings to achieve a fine homogeneous structure. If there will be no such changes, the refinement of the structure by the annealing itself is excluded. It would only be possible if the metal was cold-formed and subsequently heated above the recrystallization temperature.

For each recrystallized metal or metal that is capable of recrystallization, coarses the structure by heating to a high temperature near the melting point in such a way that the individual crystals grow and absorb smaller crystals. Coarsing of the structure is accompanied by a decrease in strength and hardness and is referred to as an overheating of the metal. Any metal, hot or cold formed, can be overheated, regardless of whether it was previously annealed.

If the metal overcomes any of the crystallization changes after the end of solidification, in most cases it is possible to rapidly suppress these changes by rapid cooling and thereby change the properties of the metal [Eperješi 2017, Glogovský 2017].

For iron alloys with less volume of carbon, it is possible to improve the mechanical properties by heating the material to the area of austenite stability and by hardening in water. Austenite is not retained because the recrystallization rate $\gamma-\alpha$ is greater than the cooling rate of the metal. $p$-iron is converted into $\alpha$, but at a high cooling rate, the carbon does not have the time to be eliminated in the form of carbide. Its atoms remain inaccessible in the $\alpha$-iron lattice. The atoms extend the lattice violently to an extent that the lattice changes its character from cubic to tetragonal with a height slightly larger than the base. This deformation of the lattice creates a large internal tension resulting in an increase in the hardness and brittleness.

\section{AUSTENITISATION}

Austenitisation is the mainstay of recrystallisation heat treatment. It is present in the area of eutectic conversion of binary equilibrium diagram of Fe-Fe3C. We are speaking about a heating above the critical temperature and the conversion of a feritic-cementitious structure in which the iron is represented in the form of a modification $\alpha$ to an austenitic structure in which the iron is represented in the form of a modification $\gamma$. In subeutectoid steels runs between the temperatures Ac1 and Ac3. Austenitisation starts in all steels by transforming the pearlite into austenite. Increasing the temperature above Ac1 results in dissolving ferrite in subeutectoid steels within the austenite. This is a diffusion transformation that takes place in the formation of austenite nuclei and their subsequent growth. The transformation of ferrite into austenite is diffusive and occurs with the formation of austenite nuclei and their further 
growth. Nucleation of austenite nuclei occurs in places of structural defects, particularly at the perlite colony interface or at the ferrite-cementite interfacial boundary. Austenitisation always starts with the conversion of a perlite having an eutectic concentration at which the austenitizing temperature reaches the lowest value. Subsequently occurs the dissolution of the proeutectoid phases which were contained in the original ferritic-cementitious structure and the carbide residues remaining in the structure after the dissolution of the perlite.

The local differences in carbon concentrations and additive elements are equalized over time, alternatively due to a further increase of temperature [Ptáček 2002, Skočovský 2002].

The process of austenitisation is affected not only by the temperature but also by the rate of its change (the rate of heating), structure and composition of the original steel. Austenitisation is fastest in steels with a fine sorbitol structure, followed by a fine perlite and the grain perlite is transformed as the very least. Austenitisation is being accelerated by the presence of carbon, while additives in the form of carbideforming elements are slowing it down.

Course of austenitisation is described by so-called transformation diagrams of austenitisation.

\section{HARDENING}

Hardening is the process of heat treatment of steels to obtain an imbalanced structural state by rapid cooling from the austenitizing temperature to form a saturated solid solution by shear transformation. The carbon saturation results in a deformation of the cubic crystallographic lattice to a tetragonal volume-centered lattice (T8). Hardening consists of heating to austenitizing temperature, persisting on this temperature (austenitisation) and cooling at a higher rate than the critical cooling rate (braking of the diffusion). Hardening temperature is determined for carbon steel according to the diagram in Fig. 1:

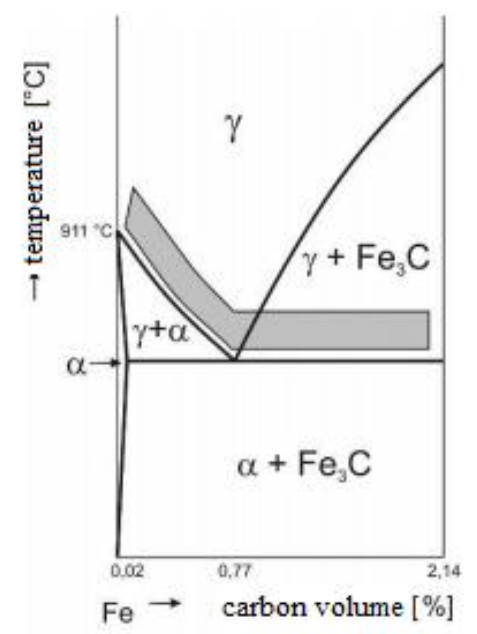

Figure 1. Area of the carbon steel hardening temperature

The austenitic degradation at constant temperature is described by the IRA (isothermal degradation of austenite) diagram and the ARA (anisothermic degradation of austenite) diagram with a continuous cooling [ČSN EN ISO 6506-1 2015, ČSN EN ISO 6508-1 2015]. For eutectic steel, the ARA diagram is shown at Fig. 2. According to the method of cooling and the process of the austenitic degradation, the hardening can be divided into:

a) martensitic hardening - the resultant structure consists of a non-diffusive mechanism of austenitic transformation into a supersaturated solid solution. The carbon saturation causes the crystalline lattice to be deformed to a tetragonal volumecentered. Thus the martensite formed has a large measuring volume and thereforearises the tension in a structure that will not allow the transformation of all austenite. Therefore, the steel structure is predominantly composed of martensite and unaltered austenite. Martensitic hardening can be divided into:

- continuous hardening - it is used mostly because of a simple cooling in one environment but not suitable for shaped alloy steel products

- angle hardening - rapid cooling above the martensite transition temperature (Ms) and subsequent cooling through the martensite area with a less cooling rate environment. As a cooling media can be used water and oil.

- thermal hardening - rapid cooling in an environment whose temperature is above the Ms temperature and subsequent cooling in the second environment over the martensite temperature interval.

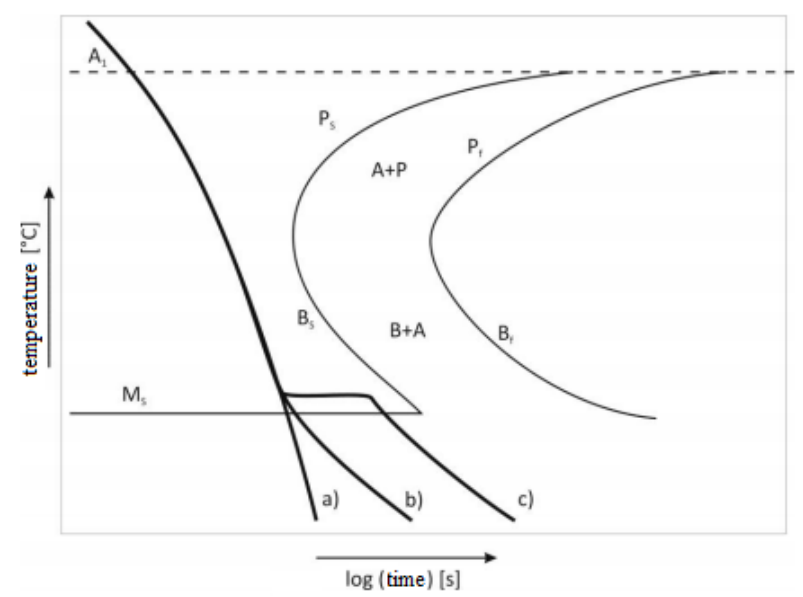

Figure 2. ARA diagram of martensitic hardening a) continuous b) angle c) thermal

b) bainitic hardening - the resulting structure is a semi-diffusive transformation. Non-diffusive transformation of austenite to a supersaturated solid solution is under way, but the rate of the cooling allows the diffusion of carbon to form the cementitious particles. Bainitic hardening can be divided into:

- continuous - formed structure is mainly bainite and martensite, followed by tempering

- isothermal - bainitic structure is formed at constant temperature, therefore there is no tempering after the hardening

\section{DESCRIPTION OF THE BODY SAMPLE}

Samples were made by turning from a circular rolled bar KR $\Phi 40$ from material EN ISO S235JR(G2). The prescribed chemical composition of steel according to the standard is presented in Tab. 1.

Table 1. Prescribed chemical composition of steel EN ISO S235JR (G2)

\begin{tabular}{|l|l|}
\hline Element & Volume \\
\hline C & $<0.17$ \\
\hline Mn & --- \\
\hline Si & --- \\
\hline P & $<0.045$ \\
\hline S & $<0.045$ \\
\hline $\mathbf{N}$ & $<0.009$ \\
\hline Al & --- \\
\hline
\end{tabular}


14 samples were made with the diameter $\Phi=30 \mathrm{~mm}$ and height of $\mathrm{h}=4 \mathrm{~mm}$ on which a hardness test was performed. In accordance with standard ČSN EN 6892-1, 14 test samples were subjected to the tensile testing.

Reducing of the cross-section of the original semi-finished product was done to remove the surface layer of the bar affected by the rolling.

The hardening process was subjected to 7 samples from each set of the test samples. Heating and tempering at the hardening temperature was performed in a Kittec XR/XT-line. Hardening parameters are shown in Tab. 2.

Table 2. Hardening parameters

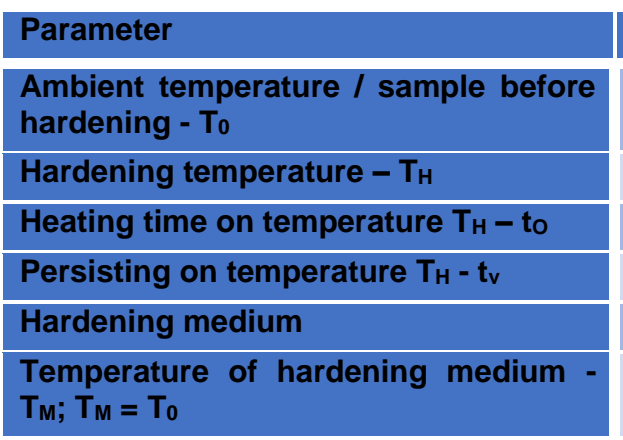

\begin{tabular}{l} 
Value \\
$22.5^{\circ} \mathrm{C}$ \\
$800^{\circ} \mathrm{C}$ \\
$110 \mathrm{~min}$ \\
$10 \mathrm{~min}$ \\
water \\
\hline $22.5^{\circ} \mathrm{C}$ \\
\hline
\end{tabular}

\section{TEST RESULTS}

When measuring the hardness according to the standard ČSN EN ISO 6508-1, Rockwell's HRC scale, the results were outside Table 3. Hardness values of HBW in the cross-section of non-hardened sample the measuring range. The team of authors with respect to the hardness of assessd steel and its structure chose to test the Brinell hardness in compliance with the ISO 6506-1. Hardness measurement was implemented. On the test samples, the measurement points were selected to monitor the change in hardness values in the cross-section of the body sample according to the Fig. 3 .

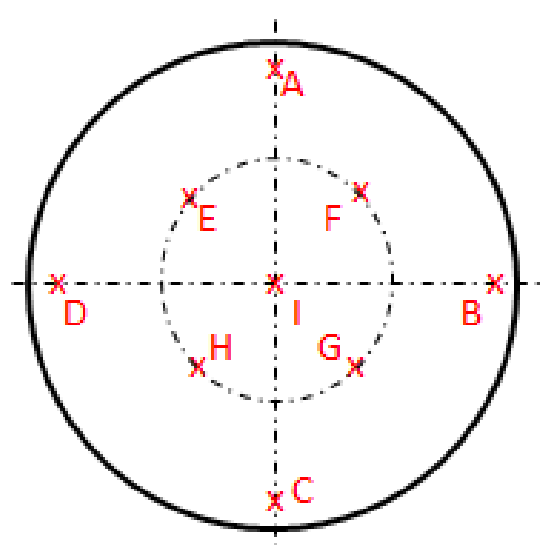

Figure 3. Distribution of measurement points

In Tab. 3, the hardness values of HBW of non-hardened steel are presented, Tab. 4 presents the hardness values of HBW of hardened steel.

\begin{tabular}{|c|c|c|c|c|c|c|c|c|c|}
\hline \multirow{3}{*}{$\begin{array}{c}\text { Sample/Measurement } \\
\text { point }\end{array}$} & \multicolumn{4}{|c|}{ Boundary zone } & \multicolumn{4}{|c|}{ Continuous zone } & Center \\
\hline & A & B & C & D & $E$ & $\mathrm{~F}$ & G & $\mathrm{H}$ & 1 \\
\hline & \multicolumn{9}{|c|}{ HBW 10/3000 } \\
\hline 1 & 134 & 140 & 141 & 138 & 139 & 140 & 141 & 140 & 139 \\
\hline 2 & 124 & 136 & 139 & 140 & 136 & 138 & 141 & 141 & 139 \\
\hline 3 & 129 & 136 & 135 & 136 & 138 & 142 & 138 & 140 & 138 \\
\hline 4 & 155 & 137 & 138 & 139 & 138 & 136 & 138 & 136 & 137 \\
\hline 5 & 139 & 138 & 136 & 134 & 133 & 139 & 138 & 136 & 139 \\
\hline 6 & 168 & 138 & 139 & 138 & 139 & 140 & 141 & 141 & 141 \\
\hline 7 & 159 & 140 & 140 & 140 & 138 & 141 & 142 & 141 & 142 \\
\hline Average & \multicolumn{4}{|c|}{140} & \multicolumn{4}{|c|}{139} & 139 \\
\hline
\end{tabular}

Table 4. Hardness values of HBW in cross-section of hardened sample

\begin{tabular}{|c|c|c|c|c|c|c|c|c|c|}
\hline \multirow{2}{*}{$\begin{array}{c}\text { Sample/Measurement } \\
\text { point }\end{array}$} & \multicolumn{4}{|c|}{ Boundary zone } & \multicolumn{4}{|c|}{ Continuous zone } & Center \\
\hline & A & B & C & D & $E$ & $\mathrm{~F}$ & G & $\mathrm{H}$ & I \\
\hline & \multicolumn{9}{|c|}{ HBW 10/3000 } \\
\hline $1 K$ & 198 & 207 & 215 & 220 & 220 & 198 & 203 & 204 & 211 \\
\hline $2 \mathrm{~K}$ & 238 & 220 & 212 & 212 & 220 & 214 & 216 & 210 & 220 \\
\hline $3 \mathrm{~K}$ & 238 & 235 & 220 & 212 & 219 & 222 & 216 & 215 & 221 \\
\hline $4 \mathrm{~K}$ & 224 & 221 & 219 & 228 & 227 & 225 & 221 & 231 & 219 \\
\hline $5 K$ & 238 & 242 & 235 & 233 & 237 & 218 & 229 & 231 & 221 \\
\hline $6 \mathrm{~K}$ & 220 & 226 & 210 & 223 & 213 & 217 & 199 & 218 & 218 \\
\hline $7 \mathrm{~K}$ & 235 & 210 & 218 & 229 & 225 & 222 & 222 & 221 & 192 \\
\hline Average & \multicolumn{4}{|c|}{223} & \multicolumn{4}{|c|}{218} & 215 \\
\hline
\end{tabular}

As it is evident from the measured values, HBW hardness has a tendency to rise from the center to the boundary zone. It is evident that when HBW values of non-hardened steel exhibit minimal cross-sectional differences, HBW variations in the cross-section of hardened samples are more striking.
Explanation of these differences is to be sought in the structure of the material and its changes due to the uneven austenitic decay. 


\section{ASSESSMENT OF METALLOGRAPHIC STRUCTURE}

The assessment of observed samples was performed on the Olympus GX51. Primary, the structure of core (Fig. 4) and the boundary zone (Fig. 5) of a non-hardened steel were observed. The structure of both monitored locations corresponds to a subeutectoid structure consisting of ferrite and perlite. The percentage proportion of individual components is approx. $80 \%$ ferrite and $20 \%$ perlite. Consistency of the structure is demonstrate by the measuring of the HBW hardness in individual locations of the samples made of the non-hardened steel. HBW hardness values varied in each zone to approximately the same average value.

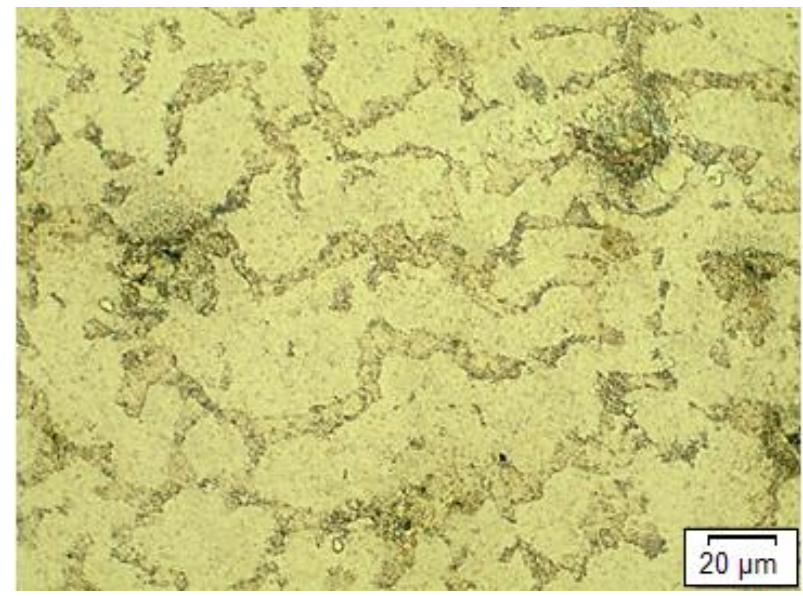

Figure 4. Core structure of non-hardened steel /50x

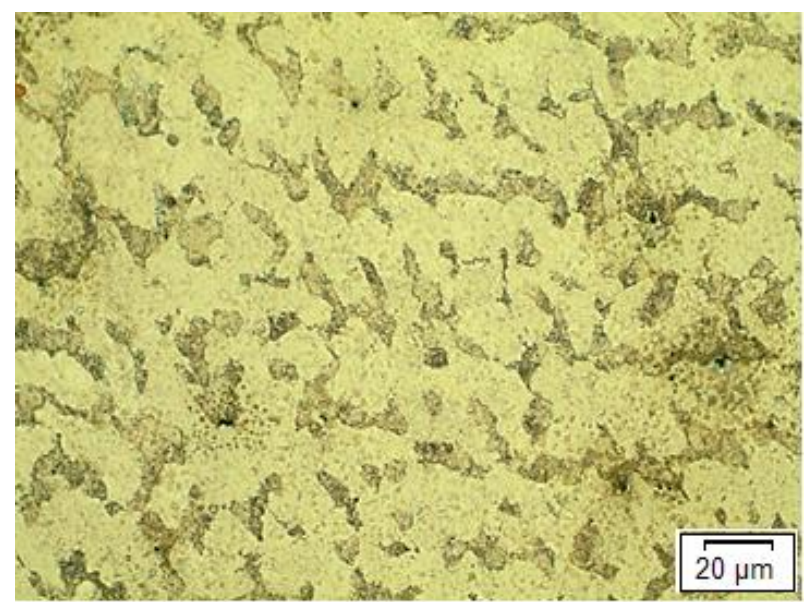

Figure 5. Structure of the boundary zone of non-hardened steel /50x

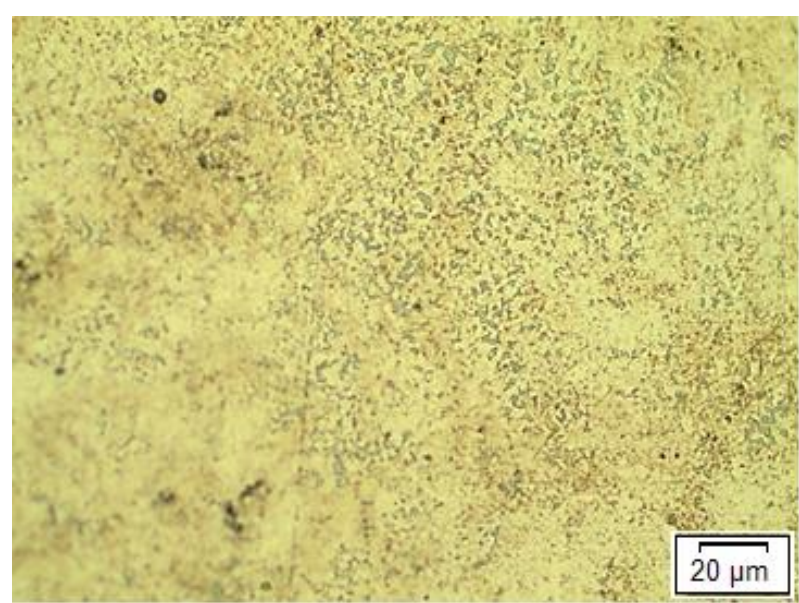

Figure 6. Core structure of hardened steel /50x

Fig. 6 depicts an image of the core structure of hardened steel test sample. It is evident that the fine-grained structure consists of a mixture of structures resulting from the austenitic degradation during the hardening. HBW hardness values are on average $57 \%$ higher compared to the non-hardened steel ones.

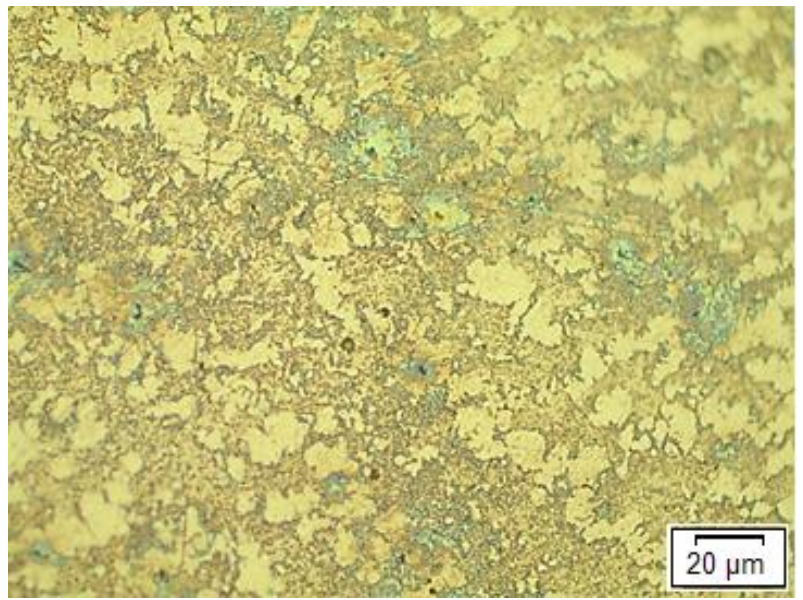

Figure 7. Structure of the boundary zone of hardened steel /50x

Fig. 7 depicts the structure of boundary zone of the sample. Comparing with etalons, it was found that the structure corresponds to the martensitic one. Martensite forms the toughest component of austenitic degradation. This explains the fact that HBW hardness values are the highest in the boundary zone of the samples.

\section{RESULTS OF STATIC TENSILE TESTING}

The tensile testing was performed in accordance with the standard ČSN EN 6892-1. During the testing, observed changes in ultimate tensile strength $\mathrm{Rm}$ and ductility $\mathrm{A}$ of hardened samples were compared with non-hardened samples.

Table 1. Tensile characteristics of non-hardened samples

\begin{tabular}{|c|c|c|}
\hline Sample No. & $\begin{array}{c}\text { Ultimate tensile } \\
\text { strength } \mathbf{R m} \\
\text { [MPa] }\end{array}$ & \multicolumn{2}{c|}{ Ductility A [\%] } \\
\hline 1. & 489.14 & 31.0 \\
\hline 2. & 486.76 & 33.5 \\
\hline 3. & 498.75 & 32.8 \\
\hline 4. & 486.43 & 32.4 \\
\hline 5. & 490.92 & 33.2 \\
\hline 6. & 495.32 & 31.6 \\
\hline 7. & 489.25 & 32.6 \\
\hline Aritmetic average & 490.94 & 32.4 \\
\hline Dispersion & 11.99 & 2.2 \\
\hline
\end{tabular}

Table 2. Tensile characteristics of hardened samples

\begin{tabular}{|c|c|c|}
\hline Sample No. & $\begin{array}{c}\text { Ultimate tensile } \\
\text { stregth } \mathbf{R m} \\
\text { [MPa] }\end{array}$ & Ductility A [\%] \\
\hline $\mathbf{1 . H}$ & 805.73 & 11.8 \\
\hline $\mathbf{2 . H}$ & 733.84 & 14.8 \\
\hline $\mathbf{3 . H}$ & 937.08 & 10.1 \\
\hline $\mathbf{4 . H}$ & 666.24 & 14.2 \\
\hline $\mathbf{5 . H}$ & 592.22 & 16.0 \\
\hline $\mathbf{6 . H}$ & 703.48 & 13.5 \\
\hline $\mathbf{7 . H}$ & 842.26 & 11.2 \\
\hline Aritmetic average & 754.41 & 13.1 \\
\hline Dispersion & 344.86 & 5.9 \\
\hline
\end{tabular}


The testing was performed on the M0128 WDW 50 tensile testing machine. The tensile testing results are shown in Tab. 5 and Tab. 6.

Samples that were not heat-treated maintain the values of the ultimate tensile strength of $\mathrm{Rm}$ and ductility $\mathrm{A}$ at a relatively constant level. By hardening, the values of the ultimate tensile strength $\mathrm{Rm}$ of the test samples were increased by averaged of 263.5 $\mathrm{MPa}$ and the ductility $\mathrm{A}$ of the hardened samples decreased by $19.3 \%$ on average.

\section{ASSESSMENT OF RESULTS}

The average hardness of non-hardened steel was approx. 139 HBW within the entire cross-section of the samples. Metallographic grinding of samples and the comparison of the structures in the individual zones of the samples showed the consistency of the composition of the structure corresponding to the minimum deviations in the hardness values.

Based on the HBW hardness measurements of hardened samples has been shown to have a rising tendency in the direction from the core to the boundary zone. Cause of this phenomenon is austenitic degradation and the formation of various structures during the anisothermal hardening. The boundary zone, as presented in the Fig.8, is formed by martensite resulting in the highest HBW values in the crosssection of the samples. The core of the samples (Fig.7) is composed of a mixture of structures resulting from the austenitic degradation. The transition zone has an increasing proportion of martensitic components.

The different structure in the individual zones of hardened samples can be explained as follows. Boundary zones of samples reached the temperature of the hardening TK in a shorter time than the core, thus achieving a longer time effect of persisting on this temperature. This led to the assumption of a complete austenitisation of the boundary zone. Subsequently, by cooling of the boundary zone, a higher critical cooling rate was achieved, which promotes the complete degradation of austenite into martensite. In the core, due to a lower critical cooling rate, the space for the formation of various structures from austenitic degradation was created, that means a mixture of bainite and perlite manifesting itself with a decrease in HBW hardness values.

The performed static tensile testing showed a significant increase in the ultimate tensile strength $\mathrm{Rm}$ of samples subjected to the hardening process. However, consideration should be given to the fact that if the non-hardened samples exhibited values of the ultimate tensile strength at a relatively constant level, the $\mathrm{Rm}$ values in the hardened samples showed the dispersion of values in the range of $344.86 \mathrm{MPa}$. A similar trend is shown by the results in the measurement of ductility $A$. Justification for this fact can be found in the carbon volume of the investigated steel. Generally, steels with the carbon volume below $0.2 \%$ are considered as non-hardenable. According to the material sheet of the studied steel, the carbon volume is $<0.17 \%$. This volume is close to the hardenability limit. The low carbon volume does not allow a uniform distribution of the austenitic decay components throughout the volume of the hardened body, in this case the testing rod. For this reason, even if the increase in the surface hardness of the hardened samples was achieved, the other mechanical properties can not be maintained within the narrow tolerance limits.

\section{CONCLUSION}

The presented contribution examines the influence of anisothermal hardening on the low carbon steel properties. The non-hardened and hardened test samples made of ISO S235JR (G2) steel, their selected mechanical properties and structural composition in metallographic grindings from individual taken samples were compared. The measured mechanical properties were HBW hardness, ultimate tensile strength $\mathrm{Rm}$ and ductility A.

Based on the results of measurements it can be concluded that the mechanical properties are directly dependent on the structure of the material, especially on the carbon volume and proportion of martensite in the structure of steel.

By conducting the experiments, an increase in HBW hardness and ultimate tensile strength $\mathrm{Rm}$ was achieved in the entire volume of test samples. The values obtained by the pressure testing were on a relatively constant level, but the values obtained by the tensile test already showed high dispersion. It follows that steels which are characterized by a carbon volume close to below the hardenability limit can be subjected to heat treatment and thus affect their properties, but components made of them and subsequently hardened can only be used in conditions where they are only subjected to a pressure load.

\section{REFERENCES}

[Brezničan 2013] Brezničan, M., Fabian, P., Meško, J., Drbúl, M. The Simulation of Influence of Quenching Temperature on Properties of Bearing Rings. Manufacturing Technology, 2013, Vol. 13, No. 1, pp. 20-25.

[ČSN 411375 1994] ČSN 41 1375. Steel 11 375. Praha: ČNI, 1994, $16 \mathrm{p}$.

[ČSN EN ISO 6508-1 2015] ČSN EN ISO 6508-1. Metallic materials - Rockwell hardness test - Part 1: Test method. Praha: UNMZ, 2015, $36 \mathrm{p}$.

[ČSN EN ISO 6506-1 2015] ČSN EN ISO 6506-1. Metallic materials - Brinell hardness test - Part 1: Test method. Praha: UNMZ, 2015, 19 p.

[Cacko 2014] Cacko, P., Krenicky, T. Impact of lubrication interval to operating status of bearing. Applied Mechanics and Materials, 2014, Vol. 616, pp. 151-158. ISSN 1660-9336

[Eperješi 2017] Eperješi, Š., Matvija, M., Bartošová, M., Fecko, D., Pribulová, A. Effect of Heat Treatment Conditions on Micro Structure of Cast Iron. Manufacturing Technology, 2017, Vol. 17, No. 1, pp. 29-33. ISSN 1213-2489.

[Glogovský 2017] Glogovský, M., Fujda, M., Balog, M., Štěpánek, M. Microstructure and Mechanical Properties of Milled Carbon Fibers Reinforced EN AW 6082 Aluminium Matrix Composites after Hot Extrusion. Manufacturing Technology, 2017, Vol. 17, No. 5, pp. 706-710. ISSN 1213-2489.

[Hluchý 2002] Hluchý, M., Paňák, R. and Modráček, O. Engineering Technology 1 - Metallography and heat treatment. Praha: Scientia, 2002, 173 p. ISBN 80-7183-265-0. (in Czech)

[Korecký 1965] Korecký, J. Heat treatment of metals (Tepelné zpracování kovů). Praha: SNTL, 1965, 88 p. (in Czech)

[Kučerová 2016] Kučerová, L., Jirková, H., Káňa, J. The Suitability of $42 \mathrm{SiCr}$ Steel for Quenching and Partitioning Process. Manufacturing Technology, 2016, Vol. 16, No. 5, pp. 984-989. ISSN 1213-2489.

[Murcinkova 2013] Murcinkova, Z., Krenicky, T. Applications utilizing the damping of composite microstructures for mechanisms of production machines and manipulator devices. In: SGEM 2013: 13th Int. Multidisciplinary Sci. Geoconf. Vol. 1: 16-22 June, 2013, Albena, Bulgaria. Sofia: STEF92 Technology, 2013. pp. 23-30. ISBN 978-954-91818-9-0. 
[Pospíchal 2015] Pospíchal, M., Dvořáková, R., Studený, Z., Pokorný, Z. Influence of Initial Carbon Concentration on Nitride Layers. Manufacturing Technology, 2015, Vol. 15, No. 5, pp. 889-893. ISSN 12132489.

[Ptáček 2002] Ptáček, L. Material Science II (Náuka o materiálu), 2nd ed., Brno: Akademické nakladatelství CERM, 2002. 392 p. ISBN 80-7204-248-3. (in Czech)

[Skočovský 2002] Skočovský, P., Podrábsky, T. Color metallography of iron alloys (Farebná metalografia zliatin železa), 1st ed., Žilina, 2002. 68 p. ISBN 80-7100-911-3. (in Slovak)

[Turtelli 2006] Turtelli et al. Magnetic and structural characterization of as-cast and annealed melt- spun Fe80xSi20Crx. Journal of Magnetism and Magnetic Materials, 2006, Vol. 304, No. 2, pp. E687-E689.

\section{CONTACTS}

MSc. Martin Podaril, PhD.

Institute of Technology and Business in Ceske Budejovice, Department of Mechanical Engineering Okruzni 517/10, Ceske Budejovice, 37001, Czech Republic

+421904157768, podaril.martin@gmail.com

MSc. Ján Majernik, PhD.

Institute of Technology and Business in Ceske Budejovice, Department of Mechanical Engineering Okruzni 517/10, Ceske Budejovice, 37001, Czech Republic

387842 137,majernik@mail.vstecb.cz

MSc. Jiri Sal

Institute of Technology and Business in Ceske Budejovice, Department of Civil Engineering

Okruzni 517/10, Ceske Budejovice, 37001, Czech Republic

380070 227, sal@mail.vstecb.cz 